\title{
Research on the Integration Model of Mechanical and Electrical Major Teaching in Higher Vocational Colleges
}

\author{
Rui Wang ${ }^{1}$ \\ 'Jiangxi Vocational Technical College of lndustry \& Trade, Jiangxi, Nanchang, 330038 \\ 278835001@qq.com
}

\begin{abstract}
This paper mainly focuses on the integrated teaching mode of electromechanical specialty in higher vocational colleges and expounds the present situation of teaching electromechanical specialty in higher vocational colleges. At present, because of the rapid development of our country's economy, the manufacturing industry is developing more and more rapidly, and the market needs more and more mechanical and electrical professionals, but because there are still many problems in the teaching of mechanical and electrical specialty in higher vocational colleges, it has hindered the development of mechanical and electrical specialty in higher vocational colleges, and also affected the effect of training mechanical and electrical professionals in higher vocational colleges.
\end{abstract}

Keywords : Higher vocational education, electromechanical, teaching integration, research

\section{高职机电专业教学一体化模式研究}

\begin{abstract}
王瑞 ${ }^{1}$
${ }^{1}$ 江西工业贸易职业技术学院 江西 南昌 330038

278835001@qq.com

\section{摘要}

本文主要围绕高职院校机电专业教学一体化模式进行研究和探讨, 同时也阐述了在高职院校中机电专业的教 学现状。目前由于我国经济的迅猛提升, 制造业发展也越来越快, 而市场对于机电专业人才的需求越来越大, 但是因为高职院校机电专业教学中还有很多问题存在, 所以对高职院校机电专业的发展形成了阻碍, 也影响到 了高职院校机电专业人才培养的效果。
\end{abstract}

关链词: 高职; 机电; 教学一体化; 研究

\section{1 高职院校机电专业教学现状}

我国工业化进程在不断加快, 而随着工业化进程 的加快，机电行业自然也获得了更大的发展动力，而 行业的发展必然会牵动教育教学的发展, 尤其是对于 高职院校而言, 高职院校教育教学的目的就是为了给 社会提供对口的专业技术人才，因此面对机电行业的 迅猛发展, 高职院校也必然要加大对机电专业人才的 培养力度。然而现在对机电专业人才培养造成阻碍的 因素就是高职院校机电专业教育教学体系。当前的高 职院校机电专业教育教学体系中还有很多问题存在, 这些问题深深影响了高职院校机电专业的教育教学 有效性。而对这些问题进行深刻的剖析, 主要可归为
以下三点。

\section{1 专业认识不清}

想要对高职院校机电专业进行恰当合理的改革, 就必须要对高职院校机电专业有完整而清晰的认识, 如果不能够做到全面认识机电专业, 对机电专业有明 确的定位, 就无法针对机电专业的教学需求设置教学 环节, 也会大大削减机电专业教育教学的有效性。机 电专业教师也首先应该抓住机电专业教学的重点, 围 绕教学重点和教学目的对学生进行教学和培养, 让学 生能够多方位的满足社会对机电专业人才的要求。 


\section{2 专业理论课程和实训课程的比例失衡}

高职院校向社会输出的是技术型人才，而技术型 人才也可作为应用型人才, 因此在高职院校教育教学 体系中应该更加注重对学生的实践能力的提升和培 养, 尤其是在机电专业教学中, 更要加强对学生的实 践能力的培养。因为机电专业属于应用型专业, 即使 学生了解非常多的机电专业理论知识, 但是如果学生 不能够将这些理论知识转化为实践能力, 也就无法满 足社会的需求。而高职院校机电专业的实训课程课时 占比太少, 无法给予学生足够的培养和锻炼, 学生所 取得的实践机会也较少, 因此虽然有了一定的机电专 业理论知识基础, 但是却无法将这些运用于实践, 严 重影响到了学生的实践能力的提升。

\section{3 理论课程教学和实训课程教学无法融合}

如今的时代, 机电一体化技术不断进步和发展, 由此也衍生了很多新的概念和工艺。一方面, 为迎合 技术的发展和进步, 很多职业院校会及时更新和改进 理论课程的内容。但是在实训课程中却没有进一步更 新和改进, 大多数院校的实训课程的内容长期不改进, 而且实训课程主要以理论验证为主, 培训也是集中性 的。另一方面, 有时实训内容会比理论内容超前, 但 是学生知识上无法随之更新, 就无法完成实训课程。 以上这些现状, 使理论课程教学和实训课程教学无法 很好地融合。

\section{4 教学方法单一}

如今高职院校的主要职责就是为国家栽培高质 量专业性人才。机电专业是当今高职院校中不可缺少 的一课, 但是机电课程的质量和机电学生的素养不是 很高, 这主要是教师教学方法单一造成的。教师在机 电课程中仍然沿用传统的教学方法, 课堂中主要以教 师为主体, 学生只是扮演倾听者的角色。教师也不及 时调动学生的积极性, 更没有及时创新教学方法。所 以这种传统的教学模式既降低了教学质量, 又削减了 学生的学习兴趣。

\section{2 高职院校机电专业教学一体化模式的研究 和探讨}

\section{1 掌握多样的教学方法与手段}

第一, 教师应该采用丰富多样的教学办法与手段, 坚持以学生为中心, 使学生在自主学习中完成对知识 的掌握。教师在教学过程中对学生进行指导与帮助, 而不只单单发挥教授的作用。教师应坚持以学生为中 心, 重点培育学生的职业素养, 提升学生的职业能力。 在选择课堂教学内容时, 应重视教学内容的指向性, 使理论联系实际, 让学生在接受教师的引导后, 能够 独立完成各项学习任务。另外, 教师应形成新的教学 观念, 为学生营造良好的学习氛围, 使学生在接受教
师的教学引导后, 能够独立投入教学活动中, 对新的 教学内容与知识进行学习。教师还需要缩短教授理论 知识的时间, 侧重于对学生实践能力的培养, 为学生 提供更多参与实践项目的机会, 使学生在完成项目的 过程中加深对知识的理解与记忆, 进一步提高自身综 合素质。综上所述，一名真正合格的教师，不仅能够 在课堂教学中传递知识, 更应该拥有完备的实践能力, 将“教学一体化”模式引入到教学过程中来。关于“教 学一体化”模式, 详细可以参考下面三种教学方法:

表 1 高职院校机电专业教学一体化模式的研究和探 讨

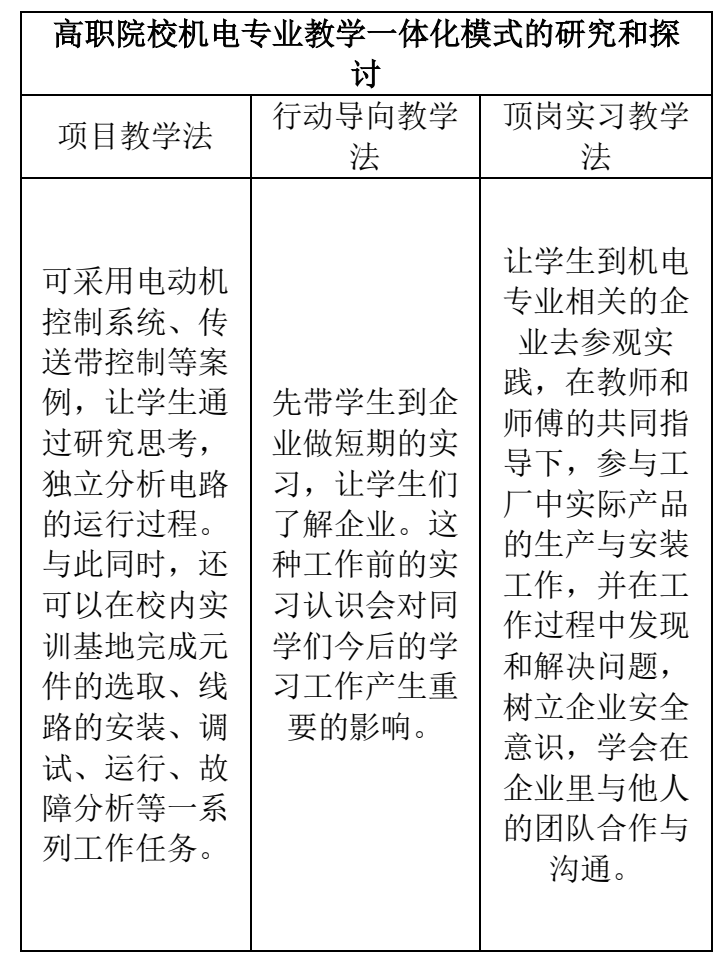

\subsection{1 项目教学法}

项目教学法在高职院校机电专业中属于较为常 见的教学方法之一。而所谓的项目教学法其实也就是 指通过项目实训内容来提升学生的各方面专业能力。 例如教师可以通过一个项目作为引导, 让学生根据教 师所布置的学习任务步步攻克项目中的难点, 而学生 完成项目的过程, 其实也就是学生锻炼自己的实践能 力的过程。当学生能够顺利的完成一个实训项目时, 学生对自己的能力也会有一定的自信, 并且项目教学 法能够有利于激发学生的潜力以及学生的学习兴趣, 同时, 项目式教学法还能够将教师所教授的知识点串 联在一起, 帮助学生构建知识体系, 使学生的知识框 架更加完整。

\subsection{2 行动导向教学法}

有部分高职院校会让学生在毕业之前就进行短 期的实习, 通过短期的实习工作, 来更加深入的了解 机电专业, 了解机电专业的知识, 并且熟悉机电方面 
工作的流程。而在学生对机电专业有了一定的了解, 也熟悉了机电专业方面的工作时, 教师就能够通过课 堂教学的方式, 来加深学生的理解, 并引导学生对机 电专业知识进行探索, 调动起学生的学习兴趣, 让学 生能够不由自主地将知识带入进实践。这样不仅能够 达到学生实践能力上的提升, 也能够丰富学生的理论 知识。不过就现阶段而言, 只有少部分高职院校使用 行动导向教学法取得了良好的教学效果。

\subsection{3 顶岗实习教学法}

顶岗实习教学法也就是指让学生真正参与到企 业工作中, 而在顶岗实习的过程中, 学生所得到的不 仅是工作经验上的增长, 也是专业能力上的提升, 因 为在实习的过程中学生不可避免的会遇到很多问题, 解决这些问题也能够有助于学生完善自己的专业能 力。在学习机电专业知识的过程中, 也许有很多问题 是学生没有发现的, 到了工作中这些问题都会一一暴 露出来, 但是发现问题并不可怕, 只要学生能够抓住 这一问题, 并予以解决, 那么学生的能力就能够得到 进一步的提升。同时, 工作还能够培养学生的团队意 识, 提升学生的职业素养。而在参与顶岗实习之前, 教师首先要将学生培养为具备一定职业能力的人才, 因此教师也应该适当的变更对学生专业能力的评定 方式, 卷面成绩只能代表学生的一部分专业能力, 但 不能代表学生的整体专业水平, 教师应该从多个角度 考察学生的学习情况, 并重视学生的个性发展, 除此 之外, 高校也应该加强和企业之间的合作, 当高校为 企业运送更多的人才时, 企业能够得到丰富的人才资 源储备, 而当企业为高校人才培养提供更多的实践机 会时, 学生也能够得到更快的提升, 而教师也能够参 与到企业的生产实践当中, 提升自己的经验的同时, 也利用自己的科研能力, 为企业做出一定的贡献。

\section{2 创立多样化、全方面的考核方式}

大部分高职院校是通过专业技能来判断学生成 绩的高低, 它们考核的目的是培养高素质人才, 使学 生拥有合格的专业技能。但随着教育的发展, 高等院 校在对学生进行考核时不能只依赖于期末测试卷, 学 校要更加注重学生的实践能力和表达能力, 从多方面 对学生的专业技能进行考核。高职院校可以采取多样 化、全方面的考核方式, 这样可以促进学生个性化的 发展, 增加学生对学习机电知识的兴趣, 从而推动学 生在学习过程中不断取得进步。

\section{3 注重实践实训环节的进行, 并使用“工学结 合”的方法}

在实践中, 实训环节需要着重强调环节具有的特 点, 比如严格性、针对性等。这就对各大高校有着一 些要求: 一、将自己学校的实训基地建设工作提上日 程; 二、建设可以长期使用的校外实训基地。通过在 校外实训基地的学习, 不仅能够让学生增加对专业知
识的储备和理解, 还可以提高学生的眼界。高职教育 有自己独有的特点: 实训课程多种多样, 因此在实践 教学中, 教师都可以充分的发挥这一特点来提高学生 的实践水平。另外, 各大职业院校要想充分的发挥好 在人才培育方面的优点就要采取校企合作, 高校和企 业相结合, 充分的发挥好各自的显著优势并结合学生 的实际情况确定课程标准、制定对人才培育的计划。 让学生在实践教育中更好的掌握专业知识和技术, 以 便于未来最大程度的适应企业的工作。当然, 开展校 企合作的企业也要严格的要求学生, 对在高校学习的 学生进行知识水平的检测, 这其中也离不开高校相关 部门对学生学习情况和教师教学质量的督促。企业和 高校在设备和人力资源方面也要学会共同利用, 不仅 要求企业中的技术人员参与到高校的教育工作当中, 比如参加讲座和报告, 还要求高校中的教师参与到企 业的生产实践当中，让企业中的员工了解更多的理论 知识和技术知识。

\section{4 增添现代机械配置数量的投入}

随着科学技术的不断发展, 机电一体化技术也在 不断创新进步, 所以校方应该要增加机电专业实践机 械的投入, 加大资金的投入力度以促进机械设备的更 新换代。这样不仅可以丰富学生的实践经验, 提高学 生的操作能力, 还可以推动机电一体化专业实践课堂 教学水平的提高。与此同时, 校方应该加强对于教师 的操作实践能力的培训, 因为教师的实践能力是学生 学习的引导, 对学生的实践能力有着重要影响。

\section{3 结语}

就现阶段而言，探索机电专业教育教学改革之路 已经成为了高职院校的关注重点。而由于高职院校不 同于其他性质院校的特点，高职院校应以就业为导向， 以提升学生的职业能力和职业素养为己任, 提升机电 专业教育教学的有效性。而高职院校在培养机电专业 的学生的过程中也必须意识到实践教学的重要性, 加 强对学生实践能力的提升, 让学生能够成为既具备一 定的理论知识也具备一定的实践能力的机电专业人 才。

\section{REFERENCES}

[1] Research on the Integration Model of Mechanical and Electrical Specialty Teaching in Vocational Colleges [J].Hurui. Chinese market,2016(15)

[2] Discussion on the Teaching Mode of Mechanical and Electrical Major in Higher Vocational Colleges Based on Vocational Ability Training [J].Jiachu Wei.Transport Vocational Education ,2009(06)

[3] Xing Yujuan, Wang Jianguo, Chen Yuku, et al. Reform and practice of the teaching mode of "integration of theory and practice, one ability and 
four cases" in animal medicine core technology course -- Taking "animal common diseases" as an example [J]. Heilongjiang Animal Husbandry and veterinary medicine (second half of the month). 2018, (3). 219-222

[4] A Probe into the Teaching Reform of Mechatronics Major in Higher Vocational Colleges [J].Hongmei Wang.Science and Technology Information ,2013(07)

[5] Exploration on the Reform of Electrical Transmission Courses in Higher Vocational Colleges [J].Wujian, Weilong Wu.Industry and Technology Forum ,2012,11(12)

[6] Wang Benqin, Wang Jiaxiang. Research on the construction of practical teaching system of landscape architecture specialty group in Higher Vocational Colleges Based on modular structure and open operation $[\mathrm{J}]$. Journal of Anhui University of science and technology, 2011, (4). 61-64

[7] Ruan Zhibin. Research on the construction of Higher Vocational Specialty Based on German Dual System -- Taking the construction of Mechatronics specialty in Changsha civil affairs vocational and Technical College as an example [J]. Science and technology information, 2017, (33). 157159

[8] Xia jieying, Liu Jie, Liu Yang, et al. Exploration of teaching mode of "promoting teaching and learning by competition" in Higher Vocational Colleges -- Taking design composition course as an example [J]. Journal of Jilin University of agricultural science and technology, 2019,28 (1): 90-93

[9] Pan Yunzhong, Liu Linxia. AHK German "dual system" mechatronics graduation examination Localization Practice [J]. Journal of Taiyuan City Polytechnic, 2015, (10). 89-91

[10] Li Dongxia. Exploration and practice of teaching mode based on working process orientation -Taking the course of fundamentals of computer application for finance and Economics Majors in our university as an example [J]. Oriental enterprise culture, 2014, (3): 340-340343

[11] Wang Qian. Analysis on the demonstration mechanism of "promoting learning, teaching and reform by competition" skill competition of software technology specialty in Higher Vocational Colleges [J]. Computer knowledge and technology, 2015,11 (17): 123-125
[12] Meng Fanzeng, Liu Longjiang, strong in study. Research and practice of "integrated" teaching mode for electromechanical integration technology specialty in Higher Vocational Colleges [J]. China Science and technology vertical and horizontal, 2012, (16): 189-190 